\title{
The Dynamic Responses of the Submersible Vehicle Mast with Different Cross-Sectional Shapes subjected to Underwater Explosion
}

\author{
Ching-Yu Hsu ${ }^{1}$, Cho-Chung Liang ${ }^{2}$, Tso-Liang Teng ${ }^{3}$ and Hai-Anh Nguyen ${ }^{4}$ \\ ${ }^{1}$ Department of Marine Mechanical Engineering ,ROC Naval Academy, Taiwan \\ ${ }^{2}$ Department of Mechanical and Automation Engineering, Da-Yeh University, Changhu, Taiwan \\ ${ }^{3}$ Hsiuping University of Science and Technology, Taichung, Taiwan \\ ${ }^{4}$ Department of Mechanical Engineering, National Chiao Tung University, Taiwan
}

\begin{abstract}
A submersible vehicle mast is a device that extended above the surface of the water while the vehicle remains hidden below. Masts mounted above a submersible vehicle are used to support navigational instruments and various electronic devices, such as radar antennas and sensors. Submersible vehicle mast must be designed to survive extreme loading conditions, such as underwater explosions (UNDEX). The present study applied the finite element method, Cole's empirical formulation and acoustic-structure coupling method to simulate an UNDEX and investigate the survival capability of a damaged submersible vehicle mast. A shape optimization problem was solved for the submersible vehicle mast models subjected to UNDEX with different cross-sectional shapes are circle, ellipse and streamline shape, respectively. The submersible vehicle mast was modelled with cylindrical shapes. First, the cylindrical and rectangular plate in an UNDEX models were conducted and simulation results are close to the failure modes shown in experiments of Kwon and Ramajeyathilagam. Second, Three prototypes of submersible vehicle masts subjected to UNDEX were presented using the same method. The results were show the model with a circular cross-section is stronger than other designs when subjected to an UNDEX. The analytical results could offer a valuable reference for submersible vehicle mast design.
\end{abstract}

\section{Introduction}

During underwater explosion (UNDEX), the sudden release of energy from a conventional high-explosive or nuclear weapon generates a shockwave and forms a superheated, highly compressed gas bubble in the surrounding water [1].

The primary concern in naval engineering and offshore structure research is predicting how submerged structures are damaged by UNDEX. In particular, cylindrical shell structures are crucial components of submersible vehicles and marine structures. Numerical methods for analysing submerged structures exposed to UNDEX have been successfully implemented. For example, Kwon [2] simulated the nonlinear dynamic response of a cylinder subjected to a side-on shock wave by using both numerical simulation and experimental (1993). Ramajeyathilagam [3] used a box model set-up under a shock tank and explosive charges of PEK-I to perform numerical investigations on thin rectangular plates subjected to UNDEX loading with the CSA/GENSA software (2004). Shin [4] presented ship shock modeling and simulation for far-field underwater explosion by applying the LS-DYNA code coupled with USA code (2004). Liang [5] studied a preliminary study of the transient responses of a 2000-ton patrol boat with shock loading using the finite element method (FEM) coupled with the second Doubly Asymptotic Approximation (DAA2) (2006). Rajendran [6] focused on the phenomenological evolution of blast damage of plates, arises from the primary concern for the design of plated structures against blast load. Zhang [7] analysed dynamic response of non-contact UNDEX on the warship and the supercharging boiler under the combination load of the shock wave and the bubble by using ABAQUS (2011). Li [8] reviewed the propagation of the shock wave and bubble pulse. The dynamic response of a cylindrical shell was examined in a water pool by using the MSC.DYTRAN software. A fluid-structure interaction method was provided to define the interaction between the water and the cylindrical shell (2012). Zhang [9] developed a procedure with the doubly asymptotic approximation method to study the problem of transient responses in a ship hull structure subjected to an UNDEX bubble (2014). Wang [10] examined the dynamic response of ship structures with the combined effect of shock wave load and bubble pulsation subjected to closein non-contact UNDEX (2014). Chen [11] conducted a numerical study of protective effect of polymer coating on the circular steel plate response to near-field underwater explosion (2015).

In the aforementioned literature the UNDEX response was primarily studied for ships and submerged structures; however, no studies exist on dynamic responses affecting 
the shapes of submersible vehicle masts. The mast is extended above the surface of the water while the submersible vehicle remains hidden below. Figure 1 shows the mast and the other systems in a submarine [12].

This study developed a procedure to investigate the dynamic responses of submersible vehicle mast exposed to UNDEX. Simulation results of the three samples were compared to determine the influence of the cross-section of the dynamic response of a mast in explosion shock wave conditions to identify the most effective crosssectional shape in three prototypes. This simulation problem was based on an UNDEX experiment in which a submerged test cylinder modelling a submarine mast was exposed to a pressure shock wave produced by a $9-\mathrm{kg}$ TNT explosive charge.

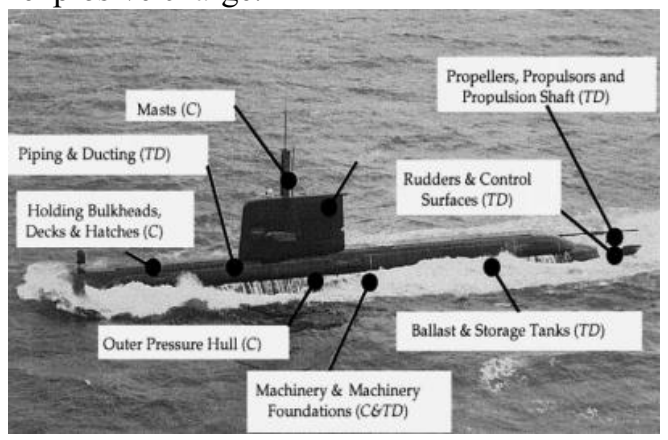

Figure 1. Submarine masts system [12]

\section{Theoretical background}

Generally the load caused by the shock wave is very high but the corresponding duration is very short (several milliseconds) showed as Figure 2.

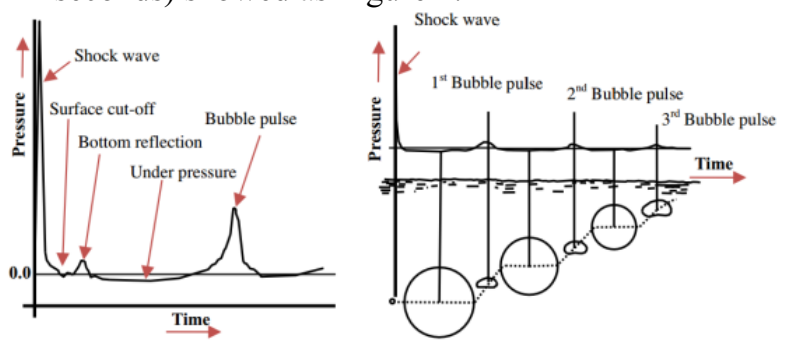

Figure 2. Phenomenon of the underwater explosion: shock wave and high-pressure bubble [1]

Empirical equations were determined to define the profile of the shock wave [1] and can be expressed as follows:

$$
\begin{aligned}
& P(t)=P_{\max } e^{-t / \lambda} \\
& P_{\max }=K_{1}\left(\frac{W^{1 / 3}}{R}\right)^{A_{1}} \\
& \lambda=K_{2} W^{1 / 3}\left(\frac{W^{1 / 3}}{R}\right)^{A_{2}}
\end{aligned}
$$

$\mathrm{P}(\mathrm{t})$ : the pressure profile of the shock wave $(\mathrm{MPa})$; $\mathrm{W}$ : the weight of the explosive charge $(\mathrm{Kg})$ $\mathrm{R}$ : the distance between explosive charge and target $(\mathrm{m})$ $\mathrm{P}_{\max }$ : the peak pressure of the wave. (MPa)

$\lambda$ :the shock wave decay constant. (ms)
$\mathrm{K}_{1}, \mathrm{~A}_{1}, \mathrm{~K}_{2}, \mathrm{~A}_{2}$ are constants which depend on

\begin{tabular}{|c|c|c|c|}
\hline $\begin{array}{ll}\text { Parameter } & \text { Charge type } \\
\end{array}$ & $\begin{array}{c}\text { HBX-1 } \\
{[13]}\end{array}$ & $\begin{array}{c}\text { TNT } \\
{[1]}\end{array}$ & $\begin{array}{c}\text { PETN } \\
{[13]}\end{array}$ \\
\hline K1 & 53.51 & 52.12 & 56.21 \\
\hline A1 & 1.144 & 1.180 & 1.194 \\
\hline $\mathrm{K} 2$ & 0.092 & 0.0895 & 0.086 \\
\hline A2 & -0.247 & -0.185 & -0.257 \\
\hline
\end{tabular}
explosive charge type, listed in Table1.

Table 1. Shock wave parameter values

\section{Validation of the numerical method}

This simulation was based on an UNDEX experiment in which a submerged test cylinder was exposed to a pressure shock wave produced by a $60-\mathrm{lb}(27.3-\mathrm{kg})$ HBX-1 explosive charge. Kwon and Fox [2] originally described the experiment with a set of selected experimental results.

The test cylinder was made of T6061-T6 aluminium, the linear elastic material model is adopted to describe the mechanical property of the material has shown in Table 2.

Table 2. Engineering properties of the T6061-T6 aluminum

\begin{tabular}{|c|c|}
\hline Property & Value \\
\hline Young's modulus (MPa) & $75.6 \times 10^{3}$ \\
\hline Poisson's ratio & 0.33 \\
\hline Mass density $\left(\mathrm{Kg} / \mathrm{m}^{3}\right)$ & 2784 \\
\hline Static yield stress $(\mathrm{MPa})$ & 300 \\
\hline
\end{tabular}

It had an overall length of $1.067 \mathrm{~m}$, an outside diameter of $0.305 \mathrm{~m}$, a wall thickness of $6.35 \mathrm{~mm}$, and 24.5-mm-thick welded end plates. The cylinder was suspended horizontally in a 40-m-deep fresh water test quarry. The 27.3-kg HBX-I explosive charge and the cylinder were placed at a depth of $3.66 \mathrm{~m}$. The charge was centred at the side of the cylinder and located $7.62 \mathrm{~m}$ from the cylinder surface. The suspension depths, charge offset, and duration of the test were selected such that cavitation of the fluid was not substantial and no bubble pulse occurred. Strain gauges were placed in multiple locations on the outer surface of the test cylinder, as shown in Figure 3.

Two pressure sensors were positioned $7.62 \mathrm{~m}$ from the charge; they were away from the cylinder, but were at the same depth as it. These sensors provided an experimental determination for the pressure versus time history of the spherical incident shock wave as it traveled by the point on the cylinder closest to the charge (strain gauge location B1). Figure 4. shows a time history curve of the incident pressure wave recorded by the sensors (experiment data [2]) and numerical simulation with incident pressure calculated by equations (1), (2) and (3).

The Figure 5. (a)-(b) shows the cylinder and field mesh and the test cylinder was meshed with 2,400 S4R finite strain shell elements. The external fluid was consisted of 45,586 elements AC3D4 acoustic tetrahedral elements. The definition of S4R element (Shell, 4-node, Reduced integration) and AC3D4 (Acoustic Continuum, 3D, 4-node) in detail are described in literature [14] and as shown in Figure 5.(c)-(d).The outer boundary of the 
external fluid is represented by a cylindrical surface with spherical ends.

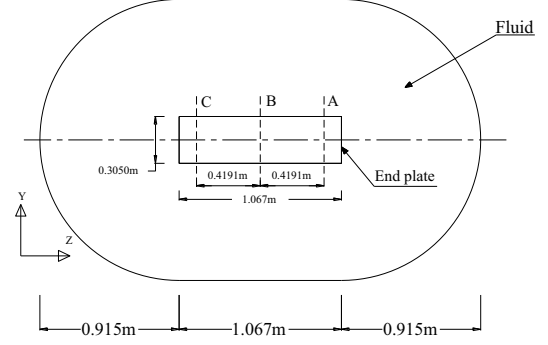

(a) Front view

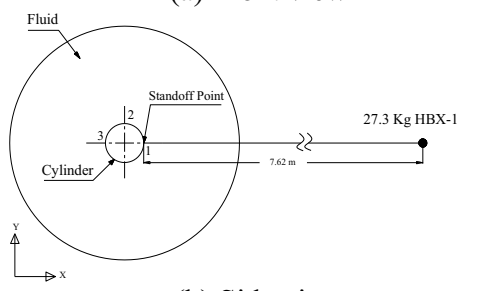

(b) Side view

Figure 3. The arrangement of the model and strain gage locations on test cylinder

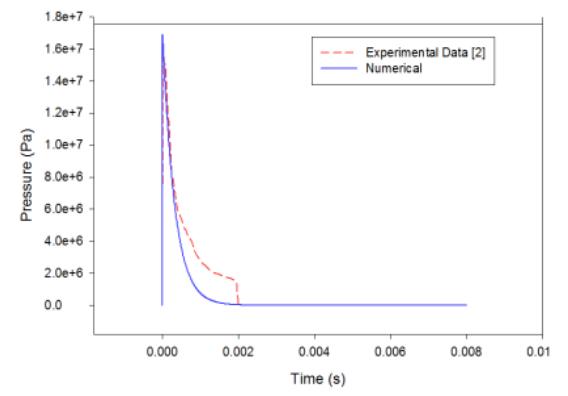

Figure 4. Incident pressure wave transient time history

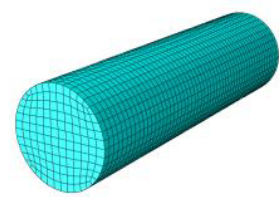

(a)

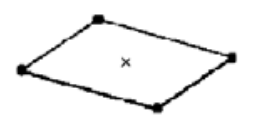

(c)

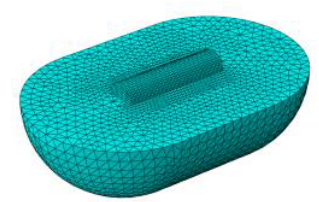

(b)

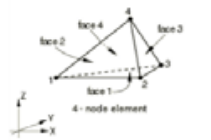

(d) (a) Cylinder mesh, (b)acoustic fluid mesh, (c) S4R element and

(d) AC3D4 element

Figure 5. Finite element model [14]

Figure. 6 to Fig. 11 contain time history of the test cylinder strains obtained from the analysis, with experimental shock loading data for locations of the strain measurements provided in Figure 3. The axial and hoop strains obtained from experimental and numerical analyses were consistent, as shown in the Figure 6Figure 11. The numerical response had the same shape as the experimental results (the numerical response according to Cole's empirical formula and the numerical response according to the experimental data [2] inputted into ABAQUS were identical). In addition, the results used for Cole's formula as shock loading input improved slightly compared with those used for the experimental value (Figure 11). However, several variations existed when comparing data between the numerical results and experimental data [2]. The data matched the experimental results closely at $\mathrm{B} 1$ and $\mathrm{B} 2$, but less closely at position A, $\mathrm{C}$ (except for axial strain of $\mathrm{C} 1$ ). Numerical and experimental results matched more closely in areas with lower values of strain.

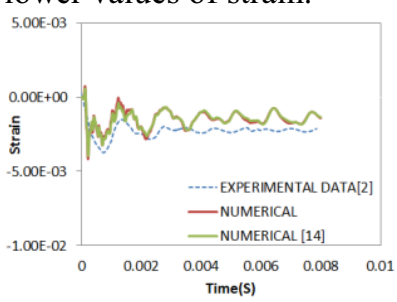

Figure 6. Experimental and numerical comparison for position A1(axial strain)

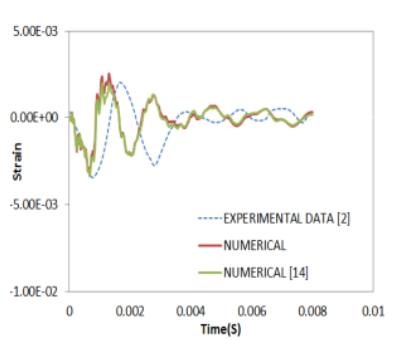

Figure 8. Experimental and numerical comparison for position B1(axial strain)

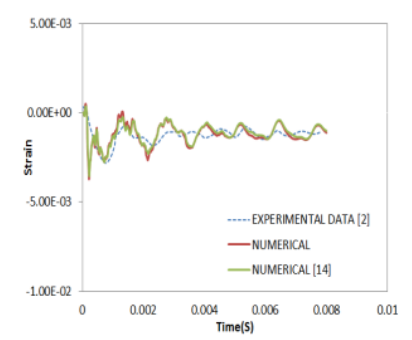

Figure 10. Experimental and numerical comparison for position $\mathrm{C} 1$ (axial strain)

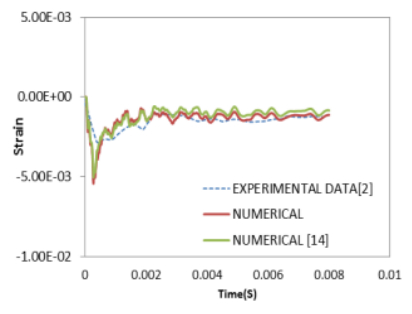

Figure 7. Experimental and numerical comparison for position A2(hoop strain)

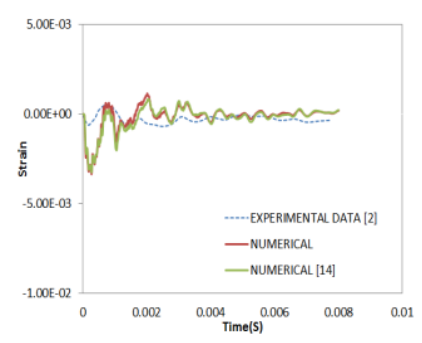

Figure 9. Experimental and numerical comparison for position B2(hoop strain)

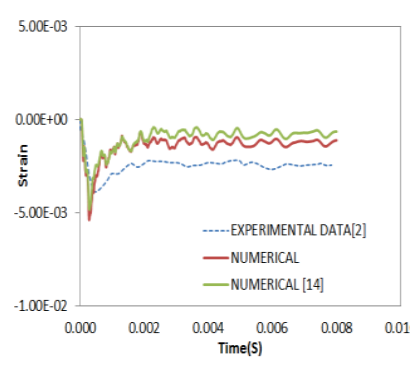

Figure 11. Experimental and numerical comparison for position C2(hoop strain)

\section{Numerical simulation of submersible vehicle mast with variable cross- sectional types}

A simplified submersible mast as a cylinder was suspended vertically in a 1-m-deep fresh water test quarry. A spherical charge of 9-kg TNT was centred at the bottom of the cylinder and located $10 \mathrm{~m}$ from the cylinder surface. The location and the simulation of the experiment are shown in Figure 12 with the source point and standoff point as they relate to an incident acoustic wave loading. The source point represented the actual physical location of the explosive charge relative to the structure; the standoff point represented the location of 
the incident wave (shock front) at the start of the analysis. In this simulation, the standoff point was placed at the point on the fluid-structure interface that was closest to the source point. A non-reflecting boundary condition was set on the surfaces of the fluid model. The boundary condition at the bottom surface of the cylinder was assumed to be fixed.
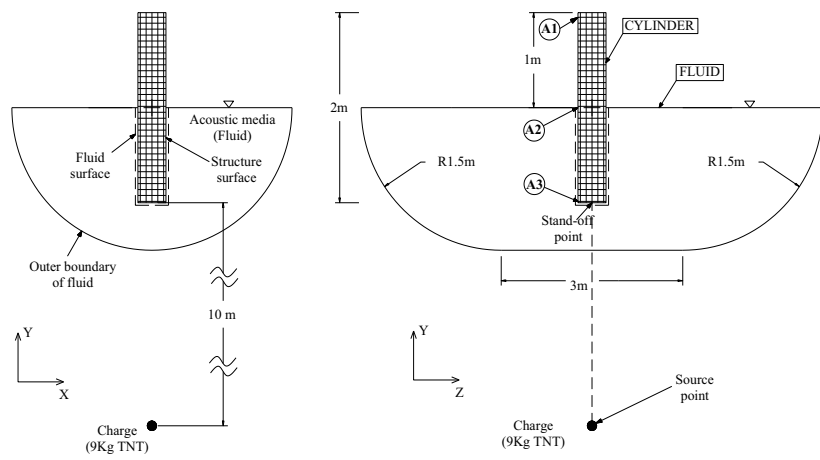

Figure 12. Schematic diagram of simulation and locations of $\mathrm{A} 1, \mathrm{~A} 2, \mathrm{~A} 3$

The test cylinder was made of steel. It had length of $2 \mathrm{~m}$ and thickness and thick welded end caps of $2 \mathrm{~mm}$. To effectively compare the effect of the cross-section of the model, three samples were created with no substantial differences. The surrounding area, weight, and height were considered factors when creating three models. The shape and circumference of cylinders are shown in Figure 13. The variable cross-sectional model was generated at the equivalent circumferential length. Three different perimeters of the cross-sectional models $(0.4398 \mathrm{~m}$, $0.4488 \mathrm{~m}$, and $0.4739 \mathrm{~m}$ ) were used to represent the three models.

The finite element model is shown in Figure 14. The mesh of Model-1 consisted of 1,067 elements; Model-2 consisted of 1,185 elements and Model-3 consisted of 1,115 elements. The element size of $0.03 \mathrm{~m}$ was set for all three models. The element connectivity was such that each shell normal was directed into the external fluid. A total of 105,000 four-node acoustic tetrahedral elements (AC3D4) were used in the model of the flow field. The outer boundary of the external fluid was represented by a cylindrical surface with spherical ends. The characteristic radius of the outer boundary was $1.5 \mathrm{~m}$. The properties of three models materials are shown in Table 3 (The elastic/plastic materials model is adopted to describe the mechanical property of Model-1; Model-2 and Model-3).

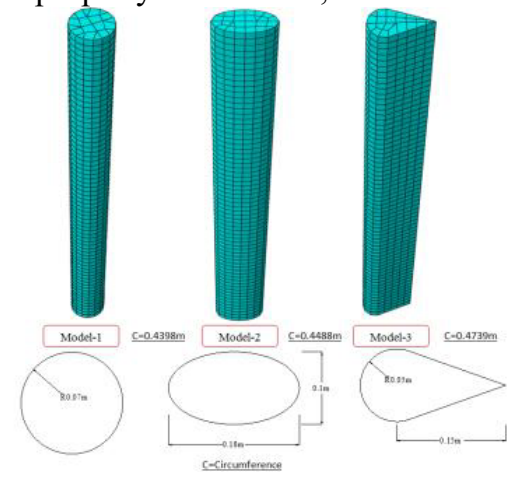

Figure 13. Three models of simplified submersible mast as a cylinder with different cross-sectional types

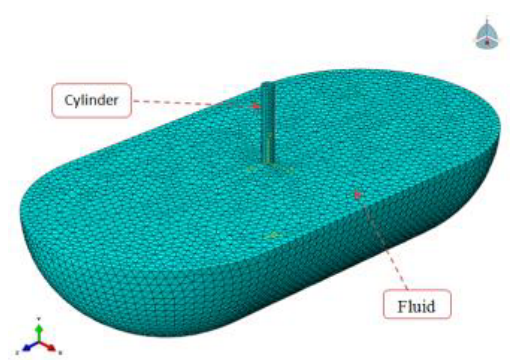

Figure 14. The finite model of the cylinder and external fluid

Table 3. Properties of cylindrical model and external fluid

\begin{tabular}{|l|c|c|c|}
\hline Material & Parameter & Value & Unit \\
\hline Steel & Mass density & 7800.0 & $\mathrm{~kg} / \mathrm{m}^{3}$ \\
\cline { 2 - 4 } & Young's modulus & $210 \times 10^{9}$ & $\mathrm{~Pa}$ \\
\cline { 2 - 4 } & Poisson's ratio & 0.3 & - \\
\cline { 2 - 4 } & Yield's stress & $400 \times 10^{6}$ & $\mathrm{~Pa}$ \\
\hline Water & Mass density & 1000.0 & $\mathrm{~kg} / \mathrm{m}^{3}$ \\
\cline { 2 - 4 } & $\begin{array}{c}\text { Speed of sound in } \\
\text { water }\end{array}$ & 1463 & $\mathrm{~m} / \mathrm{s}$ \\
\cline { 2 - 4 } & Bulk modulus & $2.1404 \times 10^{9}$ & $\mathrm{~Pa}$ \\
\hline
\end{tabular}

\section{Results and discussion}

Using the validated method in Section 3, the numerical time histories of each measuring point are shown in Fig.15. Three measuring points A1, A2, A3 were chosen on each model, as shown in Figure 12. Points A1 and A3 were chosen on the top and bottom of the cylinder. Point A2 was selected in the middle of the cylinder.

Figure 15 shows the response results of velocity. The greatest velocity occurred in Model-2 and Model-3, followed by Model-1. At position A1, the peak velocity value of Model-3 was approximately $14.7 \mathrm{~m} / \mathrm{s}$, compared with approximately $2.3 \mathrm{~m} / \mathrm{s}$ for Model- 2 and $1.4 \mathrm{~m} / \mathrm{s}$ for Model-1. In Model-3, the velocity value at A1 (top) was larger than that at $\mathrm{A} 2$ and $\mathrm{A} 3$ (middle and bottom, respectively). At $\mathrm{A} 2$ and $\mathrm{A} 3$, the velocity values of Model-2 were higher than those at the other two models. However, at approximately $0.001 \mathrm{~s}$, an upward trend appeared in Model-2 at A2 at approximately $10 \mathrm{~m} / \mathrm{s}$. In general, Model-1 showed smaller velocity values compared with Model-2 and Model-3.

Figure 16 - Figure 18 shows response of the submarine mast models from 0 to $0.006 \mathrm{sec}$. The von Mises stress of Model-2 and Model-3 rose quickly to around $5.0 \times 108 \mathrm{~Pa}$ after the $0.001 \mathrm{~s}$. By contrast, the figures for Mode-1 remained below $3.5 \times 108 \mathrm{~Pa}$ throughout $0.006 \mathrm{~s}$. A quick glance at the graph reveals that the value of von Mises stress of Model-2, Model-3 is highest. The filled contours figures illustrate the displacement responses of the whole model . These analyses showed that the response of Model-1 subjected to an UNDEX shock with a circular cross-section was a more effective shape for the submarine mast.

\section{Conclusions}

Numerical simulations of a simplified submersivble vehicle mast as a cylinder model subjected to underwater 
shock wave loading were conducted in this study, and a procedure to analyze the shock response was developed. The vlocity, displacement, von Mises stress, and time histories were obtained when a structure was subjected to underwater shock.

This study showed that the FEM, Cole's formulas, and acoustic-structure coupling method were effective tools for identifying the response of the structure subjected to UNDEX analysis. The shock wave caused by the detonation of a 9-kg TNT charge was detonated 10 $\mathrm{m}$ away from the center of the bottom of the submarine mast model.

The results indicated that with the same UNDEX conditions, the simulation results of the submarine-mast model were compared. The mast model with a circular cross-sectional form was stronger than a streamlined and elliptical shape, and can be applied quantitatively to real structural design.

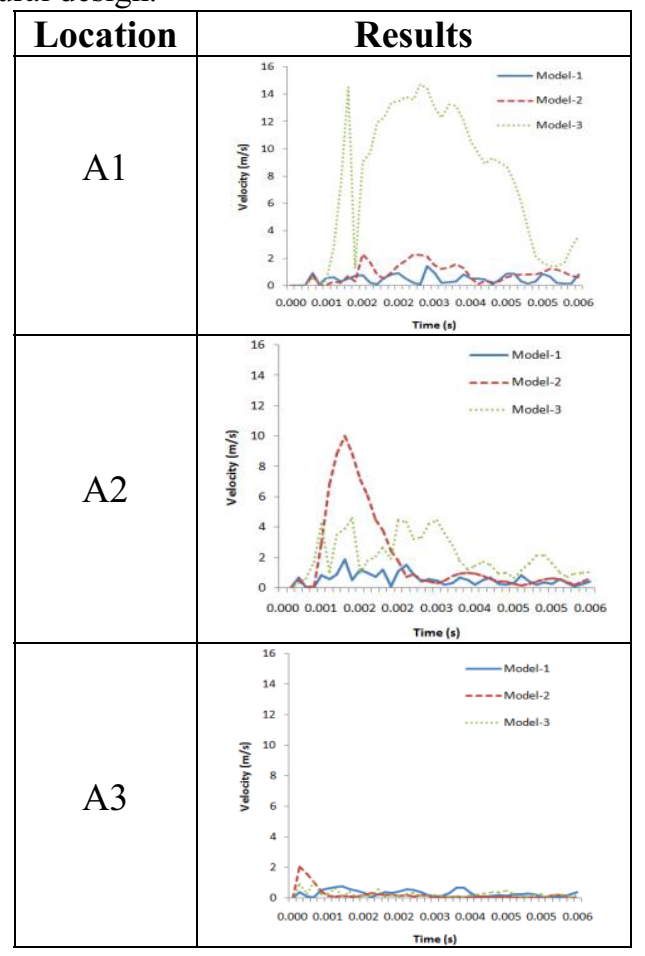

Figure 15 Time histories of velocity of A1, A2, A3
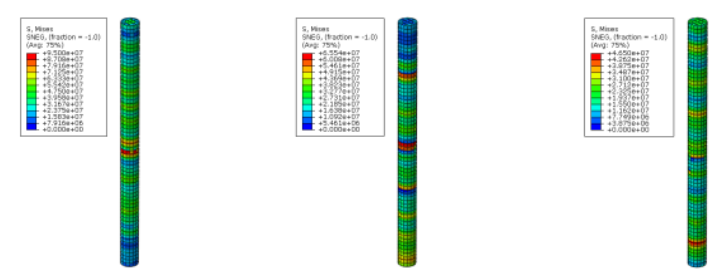

$0.002 \mathrm{~s}$

$0.004 \mathrm{~s}$

$0.006 \mathrm{~s}$

Figure 16. von-Mises and deformation response for Model-1
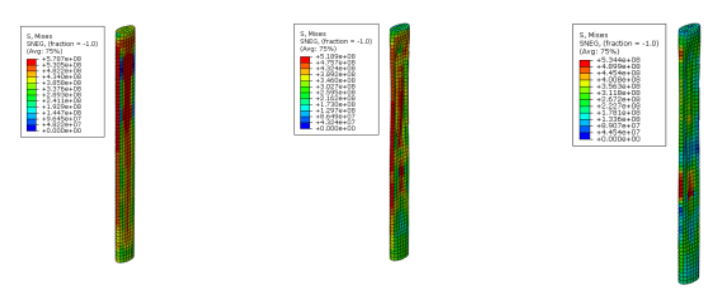

$$
0.002 \mathrm{~s}
$$

$$
0.004 \mathrm{~s}
$$

$0.006 \mathrm{~s}$

Figure 17. von-Mises and deformation response for Model-2
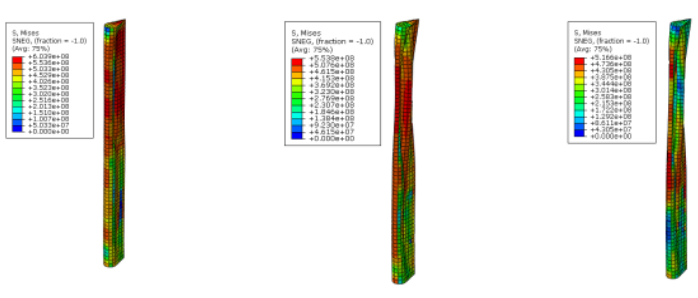

$$
0.002 \mathrm{~s}
$$

$0.004 \mathrm{~s}$

$0.006 \mathrm{~s}$

Figure 18. von-Mises and deformation response for Model-3

\section{Acknowledgements}

The authors would like to acknowledge the financially supporting this work under contract MOST-104-2221-E012-004.

\section{References}

1. R. H. Cole, Underwater explosion. New Jersey. Princeton University Press (1948)

2. Y. W. Kwon and P. K. Fox, Underwater shock responses of a cylinder subjected to aside-on explosion. Comput. Struct. 48, 4, 646-737 (1993)

3. K. Ramajeyathilagam and C. P. Vendhan, Deformation and rupture of thin rectangular plates subjected to underwater shock. I. Int. J. Impact. Eng. 30, 6, 699-719 (2004)

4. Y. S. Shin, Ship shock modeling and simulation for farfield underwater explosion. Comput. Struct. 82, 2211-2219 (2004)

5. C. C. Liang and Y. S. Tai, Shock response of a surface ship subjected to noncontact underwater explosions. Ocean Engineering. 33, 748-772 (2006)

6. R. Rajendran and JM. Lee, Blast loaded plates. Marine Structures. 22, 2, 99-127 (2009)

7. A. Zhang, W. Zhou, S. Wang, and L. Feng, Dynamic response of the non-contact underwater explosions on naval equipment. Marine Structures. 24, 4, 396-411 (2011)

8. J. Li and J. Rong, Experimental and numerical investigation of the dynamical response of structures subjected to underwater explosion. Eur. J. Mech. B Fluids. 32, 59-69 (2012)

9. N. Zhang, Z. Zong, and W. P. Zhang, Dynamic response of a surface ship structure subjected to an underwater explosion bubble. Marine Structures, 35, 26-44 (2014)

10. H. Wang, X. Zhu, Y. S. Cheng, and J. Lin, Experimental and numerical investigation of ship structure subjected to close-in underwater shock wave and following gas bubble pulse. Marine Structures, 39, 90-117 (2014) 
11. Y. Chen, F. Chen, Z. P. Du, Y. Wang, P. D. Zhao, and H. $X$. Hua, Protective effect of polymer coating on the circular steel plate response to near-field underwater explosion. Marine Structures. 40, 247-266 (2015).

12. A. P. Mouritz, E. Gellert, P. Burchill, and K. Challis, Review of advanced composite structures for naval ships and submarines. Compos. Struct. 35, 21-24 (2001)

13. W. D. Reid, The response of structure of surface ships to underwater explosions. Ship Structures and Materials Division, DSTO Aeronautical and Maritime Research Laboratory, DSTO-GD-0109, (1996)

14. ABAQUS user's and theory manuals, version 6.11.1 Dassault Systèmes, RI, USA (2011) 